\title{
Recommendations for designing games for players with dyscalculia
}

\section{Recomendações para o design de jogos para jogadores com discalculia}

\author{
Matheus Cezarotto, New Mexico State University, USA \\ matheus@nmsu.edu
}

\begin{abstract}
Educational digital games are interactive digital systems that promote learning experiences for the learner through a multimedia environment. Researchers and professionals have been using educational digital games as an intervention for children with dyscalculia. The literature demonstrates a limitation in research as regards these users' experiences with games. This study offers a user-centered design framework to investigate specific game elements that can promote and sustain users' motivation with dyscalculia during their neuropsychological treatment. It can be seen as an instance of applied research, with a descriptive goal and a qualitative data analysis approach. The study has used three main methods to inform the design of games that are better able to reach learners with dyscalculia: field research with both neuropsychological rehabilitation and game developers, and qualitative observations and interviews with players who have dyscalculia while they play math games. In addition, it offers a set of game design recommendations focusing on the motivation of children with dyscalculia.
\end{abstract}

Keywords: Educational games, Dyscalculia, Motivation.

\begin{abstract}
Resumo
Jogos digitais educacionais são sistemas interativos capazes de promover experiências de aprendizagem por meio de um ambiente multimídia. Pesquisadores e profissionais têm utilizado esses jogos como uma alternativa de intervenção para crianças com discalculia. Este estudo oferece uma estrutura de design centrado no usuário para investigar elementos específicos do jogo que podem promover e sustentar a motivação de aprendizes com discalculia durante seu tratamento neuropsicológico. A pesquisa classifica-se como aplicada, com objetivo descritivo e abordagem qualitativa. O estudo utilizou três métodos para informar o design de jogos com foco nas necessidades motivacionais do aprendiz com discalculia: pesquisa de campo com especialistas em reabilitação e desenvolvedores de jogos, bem com entrevista e observações com crianças com discalculia durante a interação com jogos educacionais. Como resultado, é proposto um conjunto de recomendações de design de jogos com foco na motivação de crianças com discalculia.
\end{abstract}

Palavras-chave: Design de jogos, Discalculia, Motivação. 


\section{Introduction}

Educational digital games are developed to promote the learning of specific content through a ludic approach: they have a clear educational goal, as well as the engaging characteristics of entertainment games (CLUAN and BITTENCOURT, 2004; MAYER, 2009). This study investigates the design of educational digital games to be used as an intervention for children with dyscalculia.

Developmental dyscalculia is a specific learning disability, children with this disorder have a severe and persistent difficulty in learning basic arithmetic facts despite presenting an adequate intellectual capacity for their age and having proper schooling (KAUFMANN and VON ASTER, 2012). Consequently, learners with this disability face cognitive, social, and motivational impairments.

Researchers and professionals have been using educational digital games as an intervention for children with dyscalculia (KADOSH et al., 2013). These games are a promising alternative in that they can offer learners a playful environment during the intervention training (GOMIDES et al., 2017). Despite the relevant contributions made by authors from neuropsychology (e.g., WILSON et al., 2006; NINAUS et al., 2017), current research does not give sufficient attention to ways games can be designed to better reach this specific area of need. This lack of awareness reduces possibilities for game-based interventions, as it ignores or pays little attention to player experience (considered a secondary element) (CEZAROTTO and BATTAIOLA, 2016).

Therefore, within a user-centered design framework encompassing different stakeholders (learners, specialists in rehabilitation, and game developers), this study focuses on the motivational aspects of using educational digital games for children with dyscalculia. Additionally, in Brazil, there is a demand for research on and the development of new educational games for children with dyscalculia (CEZAROTTO and BATTAIOLA, 2016). The goal of this study is to offer recommendations on how to best make educational math games for these learners. This study does not attempt to provide generalizable data; rather, it seeks to foster interdisciplinary discussions to improve game design and qualitative studies to address dyscalculia.

The interdisciplinary approach of this work integrates aspects of the game design field with topics from the neuropsychology of learning disabilities to enhance users' motivation. It can be seen as an instance of applied research, with a descriptive goal, and a qualitative data analysis approach. This paper contributes to the topic of cognitive accessibility demands for educational games, which deserves further research. Besides helping developers, the study may help special education specialists who wish to analyze and recommend games for their clients.

\section{Designing digital games for engagement}

Most digital games present a multimedia environment, making use of graphical images combined with text, sound effects and oral communication (TOBIAS et al., 2014). Several authors have emphasized the motivational potential of digital games and how they can be used in the 
teaching of more serious content (MALONE, 1980; MAYER, 2014). Educational digital games are developed to promote the learning of specific content through a ludic approach (CLUA and BITTENCOURT, 2004; MAYER, 2014): educational digital games have a clear educational goal oriented in a pedagogical base, which is grounded in engagement elements (see figure 1). This study uses the lens that educational games engage the player with both game elements and content, without separating the entertainment aspects from the learning.

Rieber et al. (1996) explain that educational digital games as a multimedia environment focus on the player experience. This means that the learning occurs through the player interaction with the dynamic elements of the game.

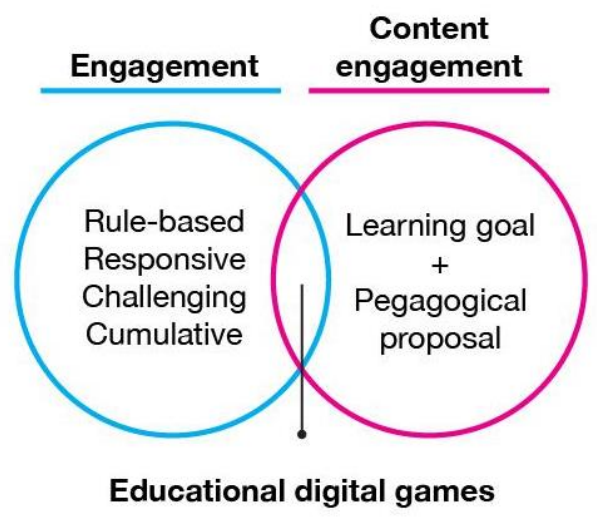

Figure 1. Graphic synthesis of the basic principles of educational digital games. Source: The author, based on Clua and Bittencourt (2004), Mayer (2014).

\section{Elements of Educational Games}

Educational digital games are systems, made of parts that interconnect to make up a complex whole (SALEN and ZIMMERMAN, 2004). In educational digital games, these parts are the game elements, with which players interact in a specific context. Various scholars have named and classified game elements in different ways. Järvinen (2008) defines the nine elements of game systems as Components, Environment, Rule Set, Game Mechanics, Theme, Information, Interface, Players, Context.

Fullerton, Swain, and Hoffman (2004) propose a complementary set of elements for the game system, using two categories: formal elements and dramatic elements. The formal elements, system) Players, Objective, Procedures, Rules, Conflict, Boundaries, and Outcome represent the functional and elementary structure of the game (FULLERTON, SWAIN, and HOFFMAN, 2004). These formal elements can be combined in several ways and represent a simple game structure. However, dramatic elements - Challenge, Play, Premise, Character, Story, World Building, and the Dramatic Arc - are necessary for a game to be meaningful for the players, allowing their imaginations to flourish into motivational and emotional experiences. These dramatic elements constitute the primary focus of this study due to their importance in stimulating players' motivation during the play experience (figure 2). 


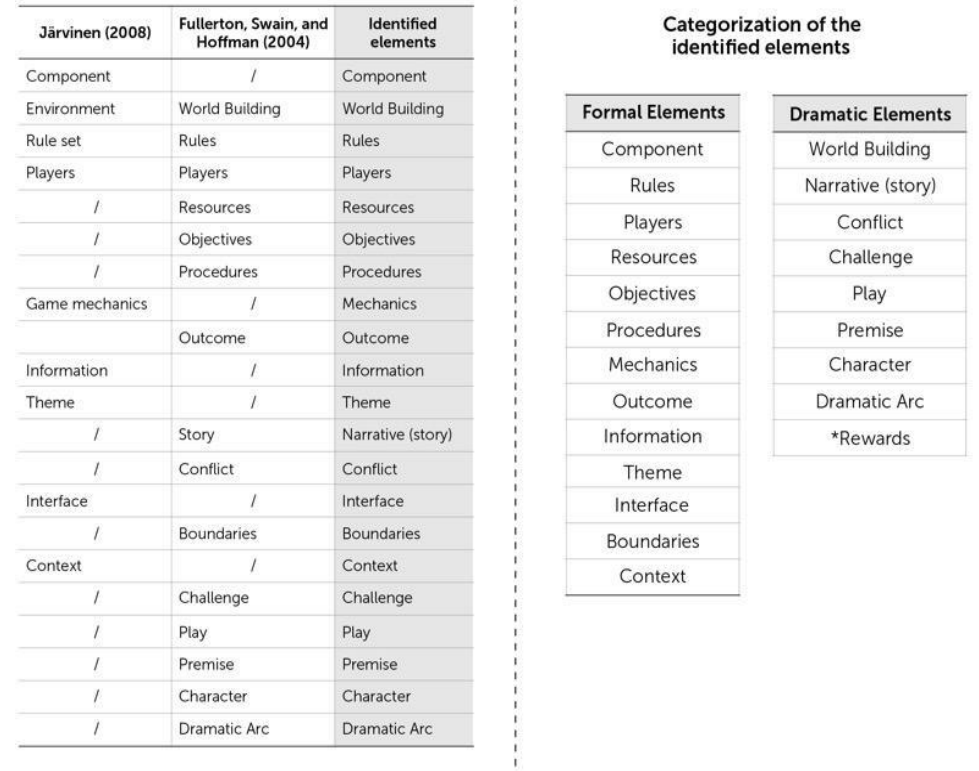

Figure 2. Game elements.

Source: The author, based on Fullerton, Swain, and Hoffman (2004), Järvinen (2008).

Elements draw on educational resources and instructional approaches to foster learning through the game activities. In summary, according to Winn (2008) and Chamberlin et al. (2012), these elements are Content Definitions, Pedagogy Approach and Educational Objective. The educational objectives and the game pedagogy represent the foundation of educational games.

The various graphical and conceptual aspects of educational digital games, all essential for the player's experience, such as game environment, characters, and rewards, have not yet been fully investigated (DICKEY, 2015). This limitation is even more significant for educational digital games for children with dyscalculia, due to the cognitive profile of these users and the specific context in which they are used.

\section{Educational Games: potential for interventions}

Dyscalculia results from a specific impairment of brain function (SHALEV and GROSSTSUR, 2001). Studies from different countries have found that $3 \%$ to $6 \%$ of school-aged children have this learning disorder (SHALEV and GROSS-TSUR, 2001; FORTES et al., 2016).

Professionals who work at the interface of health and education (e.g., doctors, psychologists, psychological pedagogues) take responsibility for conducting neuropsychological evaluations to diagnose developmental dyscalculia and provide rehabilitation. The aim of neuropsychological rehabilitation is to help the person to overcome the cognitive, emotional, psychosocial, and behavioral deficits caused by some brain impairment (WILSON, 2008).

Neuropsychological interventions based on educational digital games show promise in assisting youth with learning disabilities, particularly learners with dyscalculia (KADOSH et al., 2013). There are also cognitive advantages that learners can obtain when using games in rehabilitation (WILSON et al., 2006). Games provide an adequate level of difficulty specific to the learner's cognitive profile. This balance between learners' abilities and level of challenges 
promotes the required stimulation for progress. Players also benefit from the game's safe failure environment, immediate feedback, and unlimited practice. A further benefit is increased motivation (GOMIDES et al., 2017).

The motivation of children with dyscalculia is a relevant factor during digital interventions. However, the literature lacks research on how to design games that can facilitate math learning through engaging experiences while considering the cognitive profile of children with dyscalculia and their context of use. This study investigates this question via field research with game developers and specialists in rehabilitation and verifies the findings with children with dyscalculia.

\section{Expert's review}

This study compiles recommendations from two groups of experts on game design in this area. In the first phase, professionals involved in neuropsychological rehabilitation provided recommendations for design of educational digital games focusing on children with dyscalculia. These specialists completed an online questionnaire. The purpose of the questionnaire was to gather in-depth information on the perceptions and demands of specialists when using games with children with dyscalculia. Twelve specialists in rehabilitation completed the questionnaire.

The second phase of the field research investigated the game elements developers use to foster players' motivation in educational games. Subjects were recruited during SBGames 2017'. The game developers answered a questionnaire in person (in digital format) on a tablet (Google forms). Forty one individuals took part in this phase of the study. In both phases of field research, prior to completing the questionnaire, participants read the permission form and gave consent.

\section{Analysis of questionnaires}

The analysis of data collected through field research, both from specialists in rehabilitation and from game developers, was based on the methods of Miles and Huberman, 1994; Yin, 2001; Gil, 2002; and Cote and Raz, 2015. This process of analysis has four steps (figure 3). In the first step, Data Organization, the collected data is organized into Excel sheets. In the second step, Data Reduction, visual representations are created using a small percentage of the data collected from game developers. As part of this step, sentences and keywords from the specialists in rehabilitation are also highlighted to help identify patterns and relevant information. In the third step, Qualitative Discussion, participants' responses as well as trends in the full sample responses are interpreted qualitatively. This provides the main ideas gathered from the questions. These ideas are cross-examined and contrasted with information gathered

\footnotetext{
${ }^{1}$ SBGames (Brazilian Symposium on Computer Games and Digital Entertainment) is the largest academic event in games and digital entertainment in Latin America.
} 
through the literature review. In the fourth and final step, Drawing Conclusions, the information gathered is correlated with the specific goal that the questionnaire aims to satisfy.

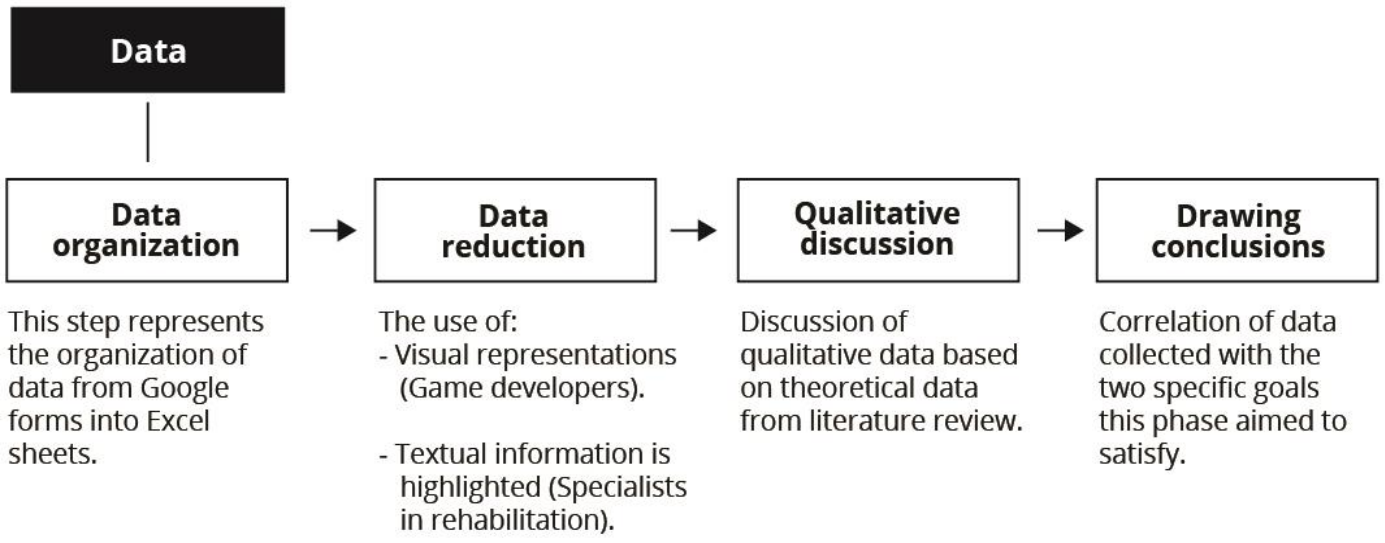

Figure 3. data analysis process. Source: The author, based on Miles and Huberman (1994), Gil (2002), and Cote and Raz (2015).

\section{Findings: Specialists in rehabilitation}

The findings from field research with specialists in rehabilitation provided three categories of educational game requirements - pedagogical support, gameplay, and game content. For pedagogical support, games need to track players' progress, time spent on the activities, and accuracy of answers. With regards to gameplay, games should stimulate the rehabilitation of children with dyscalculia by progressing activities level-by-level based on math hierarchy, applying an errorless learning approach, using repetition and novelty for the math training, and providing positive feedback. In content, the games should cover conceptual and procedural knowledge of numerical and basic arithmetic skills (e.g., base ten, number sense). To do that, specialists in rehabilitation recommend the use of visual examples from daily life. Games need to provide children with the understanding of why they need to learn that specific content. Also, games should promote math fluency and revisit concepts level by level. Figure 4 offers a visual synthesis of the data. 


\section{Games for neuropsychological rehabilitation}

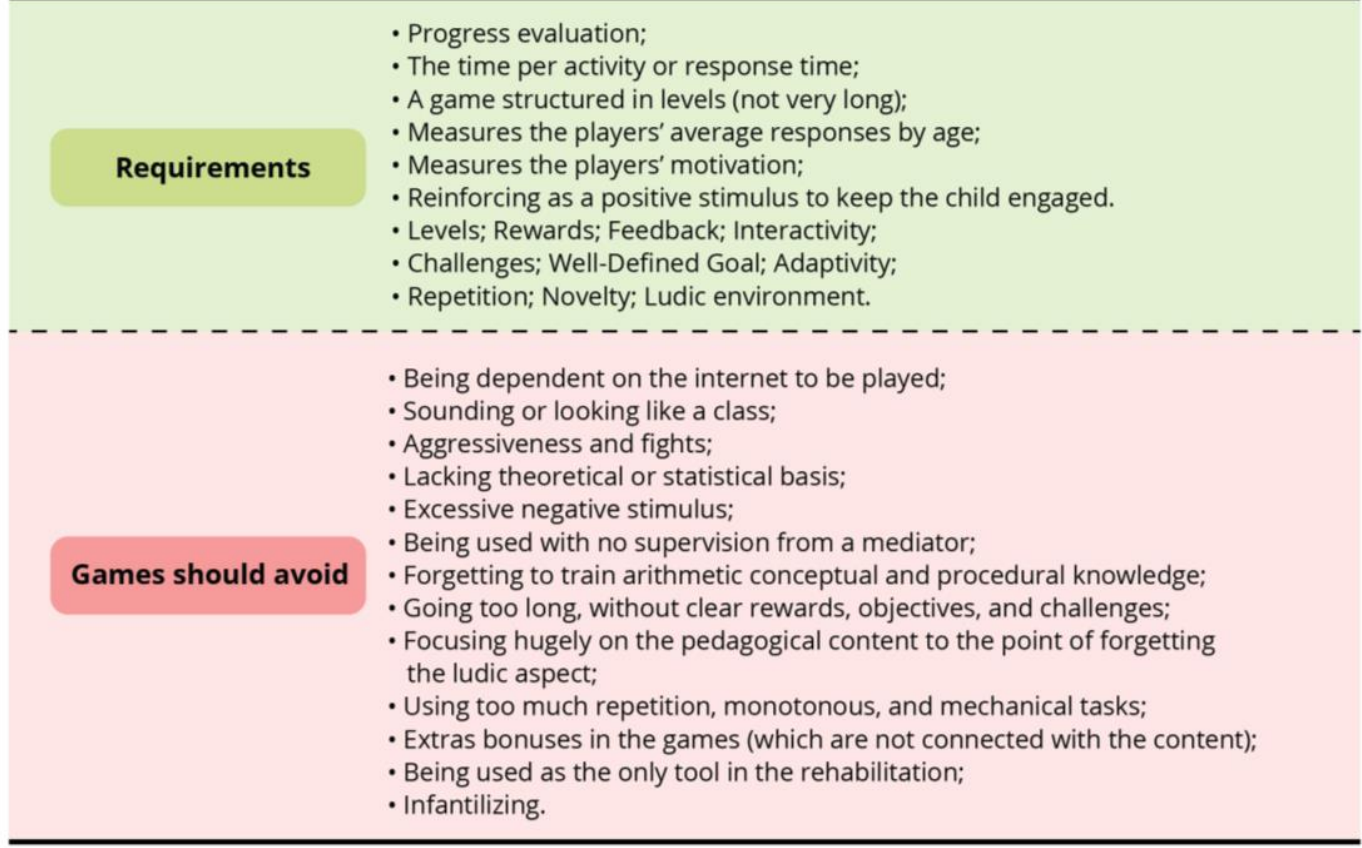

Figure 4. Summary of the specialists' data. Source: The author.

\section{Findings: Game developers}

Findings from field research with game developers provided information regarding how game elements can promote players' motivation. Developers deemed players' motivation to have a high level of importance, including the following elements: "Feedback", "Rewards", "Intuitive Interface", and "How the teacher uses the game". Although "How the teacher uses the game" is not strictly speaking a game element, for developers it directly influences players' motivation when it comes to using an educational game. In contrast, they deemed it of low importance: "To offer information about how to play" and "To offer help when the player is making mistakes."

Concerning the dramatic game elements, developers only considered the element "Rewards" very important. Developers have divided opinions regarding the level of importance of other three dramatic elements, namely, "Narrative", "Character" and "Challenging goals". This result differs from the literature, which assumes that dramatic elements play an important role in stimulating the player's imagination, emotion, and motivation in the game (DICKEY, 2015).

All the developers consulted agreed that players can help set up the game elements through co-design or user testing; however, more than half of the developers do not use a game design process centered on the player. These results show that players' participation in the development of educational games is still minimal, and not always effective. This situation can diminish the motivational and teaching potential of these games, particularly when players with special needs are not included in the design or user testing process. Figure 5 offers a visual synthesis of the data. 
41 developers (100\%) Agree that the players can help in setting up the game elements;

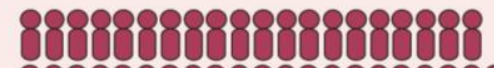

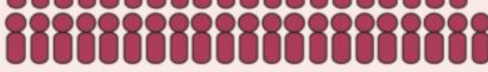

19 developers $(46,3 \%)$

Use a game design process centered on the player;

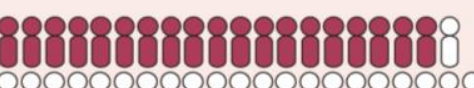
8880808080808080880808

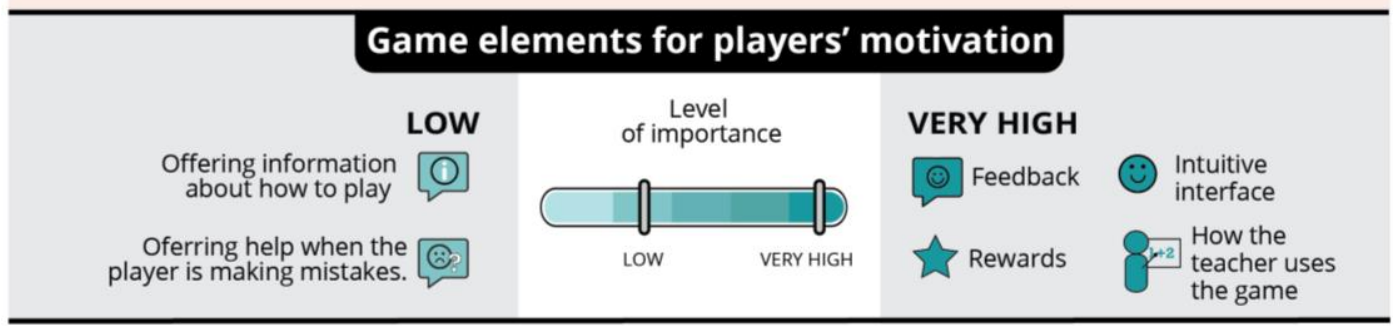

Figure 5. Summary of the game developers' data. Source: The author.

\section{Children with dyscalculia}

This study used semi-structured interviews and observations to research the experiences of children with dyscalculia. The purpose was to verify with these kids their motivational preferences in educational games, as part of their play experience. As a complement to the interview technique, the researcher made observations to enhance understanding of children's motivation during the interaction with the game.

\section{Materials}

The research used the game Monster School Bus to interact with the user (children with dyscalculia). The Learning Games Lab at New Mexico State University (NMSU) designed the game as part of the Math Snacks project (figure 5).

In the game, the player's goal is to fill up the school bus with monster kids from various neighborhoods and to deliver them to the school with as many full busloads as possible. The player is the driver of the bus and must decide the best route to pick up the children to have a full bus load (figure 6). The game allows students to visualize grouping, specifically in groups of ten, with whole numbers and decimals.
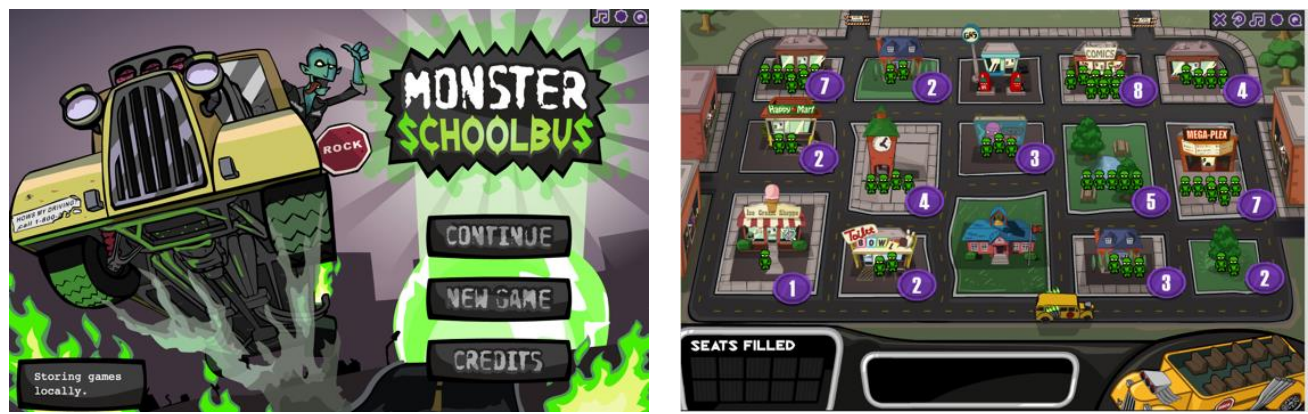

Figure 6. (Left) Initial screen from the game Monster School Bus. (Right) Screenshot from the gameplay. Source: Math Snacks website: mathsnacks.com/monster-school-bus.html 


\section{Interviews and observations approach}

The research with children with dyscalculia took place at the Developmental Neuropsychology Laboratory (DNL) at the Federal University of Minas Gerais (UFMG-Brazil). Four Brazilian children (ages 9 to 13) diagnosed with dyscalculia participated in this verification. The research with children took place in four main stages:

- Stage 1 - Consent and Assent forms: Before the first session, every child and parent/guardian read and gave permission to participate in the research. The Ethics Committee of the Federal University of Paraná and the Federal University of Minas Gerais approved the research (n. 2705139).

- Stage 2 - Ice breaker: Before starting the session, the researcher used quick and simple board games as a rapport strategy for the session (for about 10 minutes). This allowed the child to feel more comfortable with the researcher.

- Stage 3 - Gameplay: Each child played the game Monster School Bus for 20 minutes per session. During gameplay, the researcher observed the child and took notes of verbalizations, main difficulties, and level of engagement with the game.

- Stage 4-Interview: After having played the game the children were interviewed for 30 minutes). The general aim of the interviews was to obtain information about the children's motivation during the game and their preferences.

To summarize, each child played a game under the researcher's supervision for approximately twenty minutes, once a week over a period of three weeks. Each session lasted one hour and was composed of three main activities (figure 7): (1) 10 minutes of rapport, playing board games; (2) 20 minutes of gameplay with the game Monster School Bus; (3) 30 minutes of interview, after the gameplay.

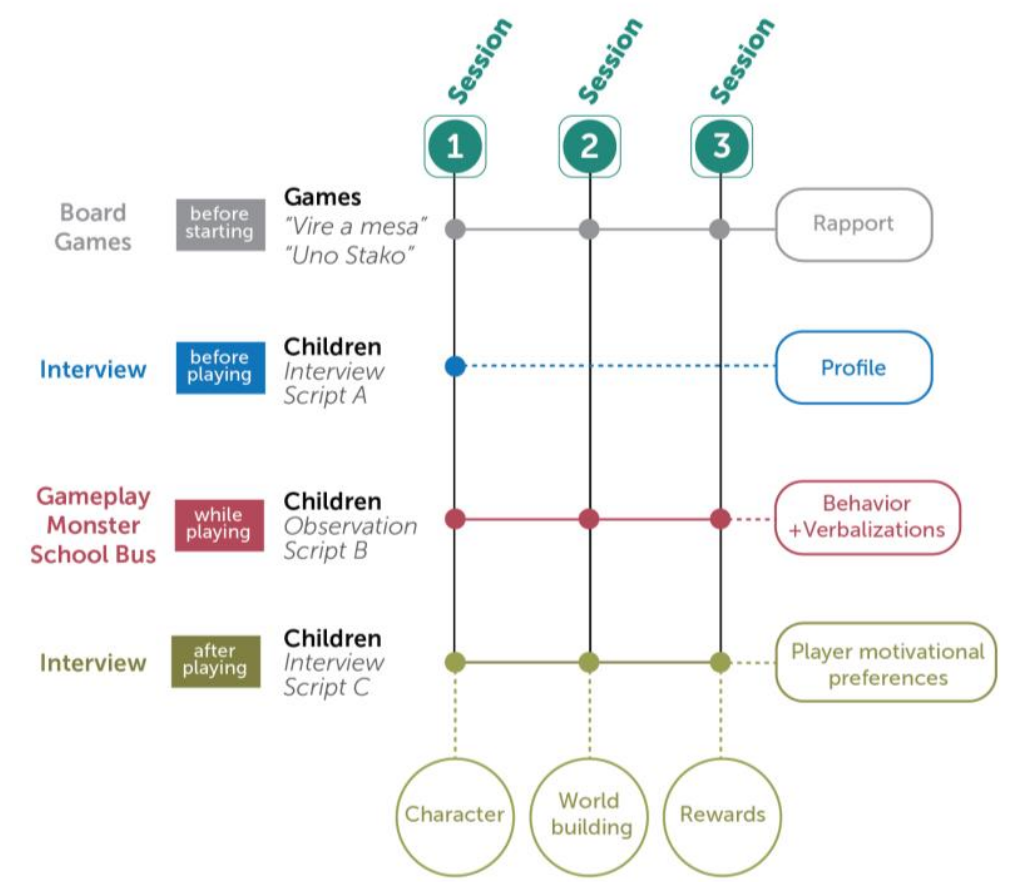

Figure 7. Summary of the interviews and observation methodology. Source: The author. 


\section{Data analysis strategy}

Data were analyzed using triangulation. This strategy allowed researchers to cross-examine information/data from different sources (YIN, 2001) within the research with children with dyscalculia. As previously mentioned, this study proposed a data analysis strategy for qualitative data (figure 8). Firstly, the data from different sources (interviews, observations) were organized in an Excel table according to child and session (data organization). The information was then categorized and coded (data reduction). Once coded, the data were analyzed qualitatively correlating the sources (qualitative discussion). Finally, conclusions were drawn considering the data concerning the child and the group (drawing conclusions).

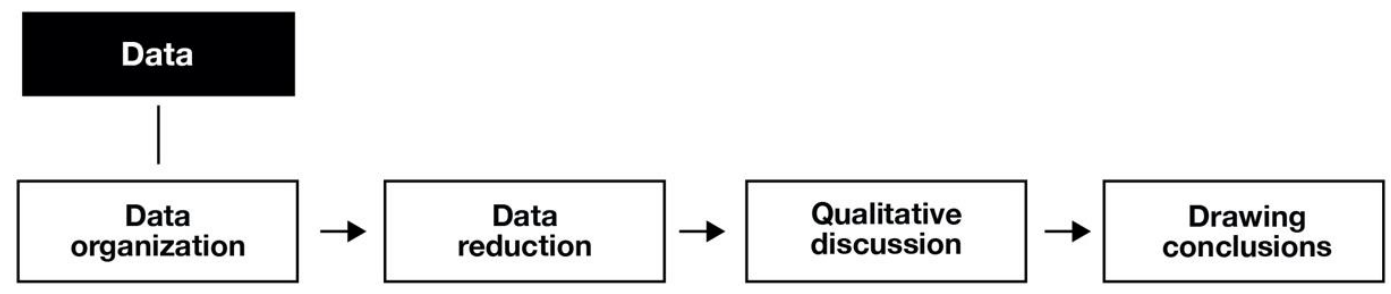

Figure 8. Steps for the qualitative analysis in this study triangulation. Source: The author, based on Gil (2002), Cote and Raz (2015), and Yin (2001)

\section{Findings: Children with dyscalculia}

Four Brazilian children participated in the research, one boy and three girls (ages 9 to 13). Participants were in 5th to 8th grade. All of them had the diagnosis of developmental dyscalculia, and had some comorbidity, such as attention deficit hyperactivity disorder (ADHD) and/or dyslexia (figure 9).

The data from the interviews and observations showed that the game Monster School Bus was able to promote and sustain participants' motivation (figure 9). Although the game proved to be too difficult for the participants, they remained engaged in the game, mainly because they were curious about the new characters (monster kids), the new challenges, and about the end of the game story. Participants were also curious and excited about the final game reward. The fact that the game system did not prevent any of the participants from moving forward or from finishing a level also contributed to keeping participants engaged in the game.

The interviews and observations identified several players' preferences concerning the game elements. Their preferences served as a bottom line to build the game design recommendation, presented in the following section. 


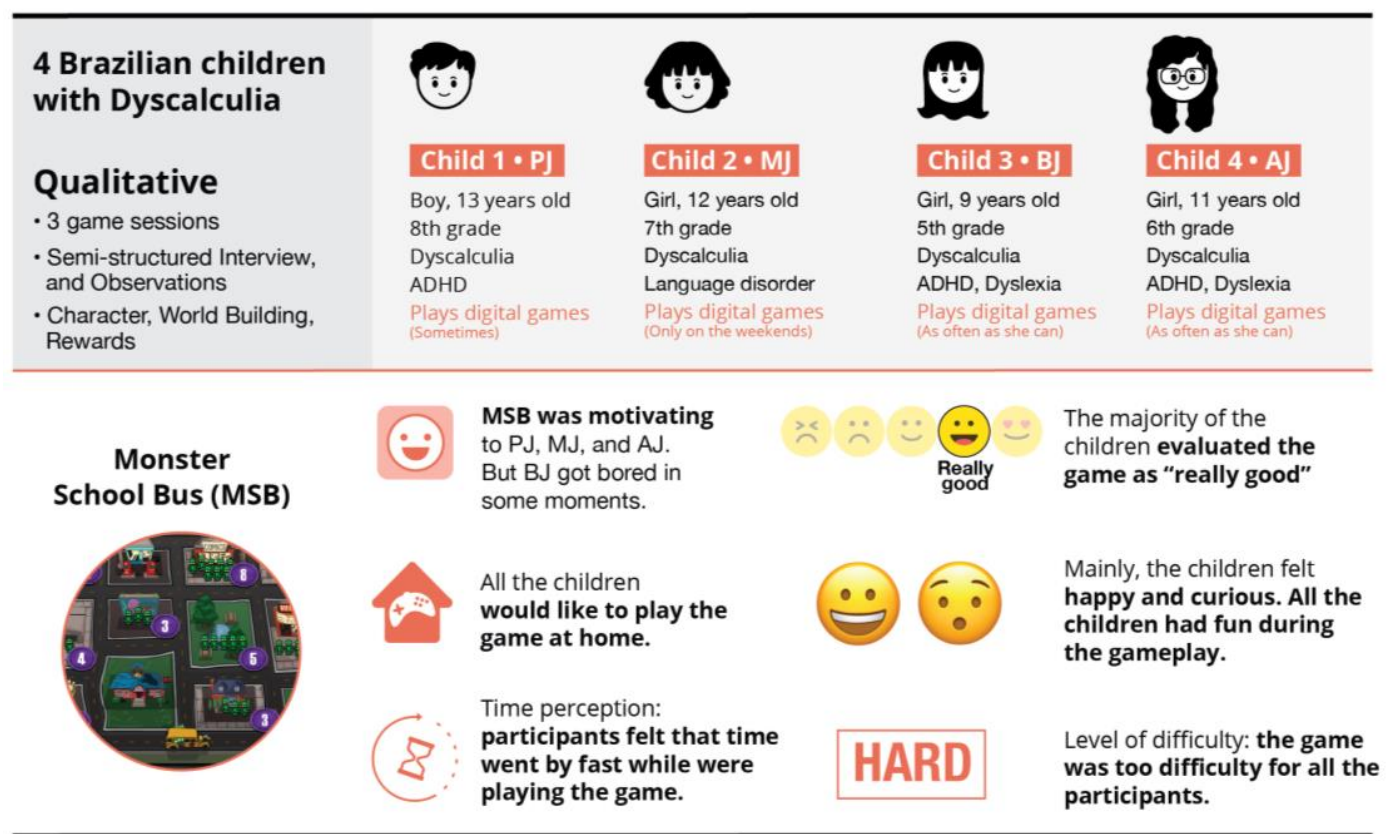

Figure 9. Users' data, visual summary. Source: The author.

\section{Game Design Recommendations}

The game design recommendations of this study have as their starting point the recommendations found in the literature and those made based on the results of the field research (with game developers and specialists in rehabilitation). As a final step, this study further developed these recommendations based on the preferences of children with dyscalculia (using data from the user verification). The various recommendations from the children overlapped and had a lot in common. However, to organize them for this study, they were classified into three game dramatic elements: Character, World Building, Rewards.

\section{Character}

In the interviews, children with dyscalculia emphasized that they expect to engage with a character in an educational game. They explained how a game without a character would strike them:

PJ: "I think it's not going to be cool because it is like the character was the essence of the game. Where is the character? It has to have a character, right? It has a story, right? Then it should have a character".

AJ: "It would be boring. Because without it the game is boring. He (referring to the game character) changes everything".

Also, one girl (BJ) highlighted her expectations about character representation. For her, if the game does not have a female character: "Ah, no girl will want to play the game". But if there is no character at all, "Then no one will want to play. The game needs to have one, or two or three characters". Based on this data the following recommendation was outlined: 
- Provide a character and options for the player selection. Children with dyscalculia expect to have different characters to choose from in educational games, at least one male and one female option. Diversity of gender representation seems to allow these learners to relate better with the character.

As regards the possibility of choosing or customizing the game character, children with dyscalculia said:

PJ: "It would be good, right? Because in this case the person would think "Really! I can customize him!" It would be more fun, he would design his own character and also the bus. [...] Also, you know... for example we could customize our bus in the middle of the game. You know, it makes the game more dynamic".

BJ: "[...] with customization you can choose how you want your character, if you would like a man, with hair or no hair. I would make changes to him during the whole game. $[\ldots]$ because in real life you don't cut or stick a flower and so on. But with the game character, you will be able to remove, to cut and to stick things".

MJ: "I think it is very cool, to see how your imagination works, right?".

About this, AJ explains how she thinks customization of the game character can help to prevent a game from being boring. For her, this possibility is cool "[...] because if you keep it the same, then you have the same thing, and it gets boring". So, her idea is that the game could allow players to change characters during the levels. "Sometimes I would play with the same one in two levels, and then in the other two levels I would choose another one (referring to the character)". Based on these pieces of evidence this study outlines the following recommendations:

- Use different characters in different levels or different game worlds, to foster players' curiosity and maintain players' motivation. Players with dyscalculia like when new characters appear at new levels and become curious about the new characters.

- To prevent children with dyscalculia from losing interest during the gameplay in an intervention, games can use character customization as part of level design. Children with dyscalculia consider a game 'cooler' when they can customize the game characters (e.g., hair, clothes, add new powers).

Considering the cognitive profile of children with dyscalculia, these learners usually face difficulties in learning math. For instance, during gameplay of Monster Schoolbus, all the participants struggled to deal with decimals. Thus, when asked if the game character should give players tips about the game challenges, children with dyscalculia said:

PJ: "Ah, this would be good because it helps. Only in a very difficult moment. Or advice like, in a challenge when you need to do something extra. For example, when you need to take all the flasks with the potions. It would be an instruction".

MJ: "I think it's a lot better to get through the game, to see how you do it. [...] only when I'm having difficulty, otherwise it gets too easy".

AJ: "Ah, it would make it a little easier. So, for example, you are doing very badly, then he (the character) goes there and gives you a tip, then you do better". 
Participants thought it would be better to receive performance feedback from the character. They also thought the character should be honest and tell players when they performed poorly so that they can improve. They also felt it would be 'cool' to receive instructions on how to play the game from the character as part of the story. Regarding the character giving tips in the game, participants thought this would make the game easier, would allow players to progress when they were stuck and would help them with new tasks. However, the participants stressed that this should only occur in very hard challenges; otherwise, it would be too easy, and the game would become meaningless. Based on this evidence, this study outlined the following recommendation:

- The game system can use characters to communicate with the player. Players with dyscalculia prefer that the game character give instructions about the game challenges and on how to play the game, as well as feedback on their performance. Children with dyscalculia prefer to receive tips only in very difficult challenges, otherwise, it would be too easy, and the game would be meaningless.

\section{World building}

The researcher asked participants to imagine what the game would be like without the story. The children with dyscalculia said:

PJ: "It won't make any sense, right? Because, there are some moments when he talks to the boss. So, that creates a little of... since when he has this job? How did he get into this job? It should have these things".

MJ: "It would be...no one would know how she took the bus if she really wanted the job".

BJ: "Then it would make no sense. Because it does not have a story. Then it is not possible to understand anything. [...] you won't understand anything, and you won't be able to play. You will want to know how many kids you need to pick up, but you can't, then you won't understand the game".

AJ: "Ah, you would not know what you were doing in the game".

Participants understood the game story as one of the main elements that created the game sense for them. Based on the game story, players understand the purpose of the character and the game challenges. About this, PJ also said that there should be a tutorial explaining how to play the game: PJ: "[...] it is very good that the games always have a tutorial to explain how to play. Because if we don't have a tutorial, we just get confused, like in some of the games that I played that didn't have a tutorial". Based on these pieces of evidence, this study outlined the recommendation.

- Players with dyscalculia expect a connection between the character and the story in the educational game. Use a narrative to create the game sense and introduce the content.

- Create a tutorial teaching players how to play the game and make it part of the narrative. Players with dyscalculia feel more confident when they understand the goals of the game. 
Participants shared their thoughts on if the game story should teach about the game challenges or tasks:

MJ: "it would be cool to receive some tips. Then it would be easier to get the kids. Also, it would be much easier to get the potions".

BJ: "It would be easier, right? Because then you would already be thinking about how you would do the challenges, right?"

AJ: "It would be better, but it is also good that we go on learning, right? Playing the game and learning".

For participants, players need to understand the story to play games. For them the story is necessary to help players to understand what is going on, and what will happen in the game. BJ explains that otherwise, it would be horrible because the player would not understand anything and would not be able to play. For PJ: "It's good because if we understand the story, then we understand a little bit what we need to do, right? Because it is there, right? [...] People always like to play games that have a story because they want to find out about the ending, right? Like in the movies". Participants connect the story with the game tasks, to understand what they need to do in the game. Also, the story brings an element of curiosity to the game, which can make players curious to find out what will happen in the end. Based on this data, this study outlined the following recommendations:

- Use a narrative to provide clear instructions. Players with dyscalculia enjoy fantasy in the game narrative, provided that the narrative makes sense to them. The narrative should make it clear to players what happens to the character, why the character is taking action and what for.

- Create a game narrative that fosters curiosity about the game levels, characters, and challenges. A narrative that fosters curiosity in the player makes them want to continue to play the game in the intervention.

- Use elements of surprise and novelty in strategic moments in the story as a way of preventing players with dyscalculia from losing interest in the activity.

Participants had enhanced memory of funny moments from the game narrative. For instance, during the gameplay observations, $\mathbf{B J}$ remembered some funny parts from the game narrative and happily shared them with her mom. Also, during the interview participants described funny moments when asked about what they think about the game narrative. Based on this information this study outlined the recommendation:

- Use funny moments to catch the player's attention; children with dyscalculia tend to remember narrative moments that have humor more easily.

\section{Rewards}

The researcher asked participants to imagine what the game would be like without the rewards. They said: 
PJ: "Huh, it is because the car (referring to the final game reward) works as a way to make us curious. If we get all the stars, right? Then, it makes everyone curious. [...] Ah, any type of reward is good. And any reward can be used, whether it is bad, good or more or less. [...] it shows where we need to improve".

MJ: "It would be boring because it would have nothing. Then you don't enjoy playing the game. [...] good to make the player stay more time playing, to devote himself more to the game".

AJ: "You would not know if you did well. Because in most of the games you need to get the stars, because sometimes when you do not get these stars, you do not know how many points you scored".

Participants consider a game with no reward boring. They consider that players would not enjoy playing the game; players would not know how well they were performing, because for them the sense of reward relates to the player's score. A good reward should make the player want to spend more time playing because it gives them pleasure. Also, a 'cool' reward should foster curiosity and motivation and encourage the player to perform well. Based on this data this study outlined the following recommendations:

- Use game rewards as a strategy to contribute to the development of children with dyscalculia skills and increase their engagement and level of immersion during the game activities. Rewards can increase players' self-efficacy as the game system gives them feedback according to their efforts.

- Educational digital games should have different types of rewards. Players with dyscalculia expect rewards and consider a game with no reward uninteresting. Rewards affect how much pleasure players have in playing the game.

- Create a connection between the acquisition of knowledge and the game rewards. Use rewards strategically to show players with dyscalculia their progress, highlighting what they have done (learned) and what they can still earn (learn). During game-based interventions, children with dyscalculia like to know that they are learning, and that playing the game is worth their efforts. This can increase these players' self-efficacy and motivation.

\section{Conclusions}

Designing for accessibility is an important aspect of meeting the needs of all users. We are all on a spectrum of need (temporary, situational, or permanent), which means that we all need a degree of accessibly to use any product (digital or analog). Addressing a wide range of users' needs allows the design team to remove interaction barriers during the game experience. However, making accessible games is complex and demands constant improvement from the design team in terms of frameworks, technologies, and user testing approaches. This study brings contributions to the cognitive accessibility demands for educational games, which is a topic that still needs much research. 
This study offers a set of game design recommendations to promote and sustain the motivation of children with dyscalculia. The detailed game design recommendations have the potential to help game development teams design math games which are more accessible to players with dyscalculia. These findings may also help special education specialists who wish to analyze and recommend games for their clients.

The effectiveness of these recommendations in fostering player motivation will largely depend on how creative teams will interpret and apply the recommendations during the design process. It will also depend on how professionals will use games with dyscalculic children as part of their treatment. Finally, these findings reinforce that it is essential for developers to consult players with dyscalculia during the design process.

\section{Acknowledgments}

This research was carried out as part of the author's doctoral studies at the Design Postgraduate Program of Federal University of Paraná, Brazil. The author would like to thank the financial support of CAPES and CNPq:

- This study was partially financed by Coordenação de Aperfeiçoamento de Pessoal de Nível Superior - Brasil (CAPES) - Finance Code 001. The six months spent at the Learning Games Lab (NMSU) were financed by CAPES, as part of the Sandwich Program (2018).

- This study also received financial support from CNPq as part of the research project "Design de jogos para crianças com discalculia do desenvolvimento", process number: 409770/2016-7.

Also, thank you the Developmental Neuropsychology Laboratory (UFMG, BR) and the Learning Games Lab (NMSU, US) for their support and contributions to this study. The Math Snacks project has support from the National Science Foundation (0918794 and 1503507). A special thank you to Dr. Barbara Chamberlin for her valuable contributions shaping this study. And to Dr. André Battaiola for his guidance during the author's doctoral studies. Thank you to Amy Smith Muise for proofreading and improving the written quality of this paper.

\section{References}

CEZAROTTO, Matheus; BATTAIOLA, André. Game Design Recommendations focusing on children with developmental dyscalculia. In ZAPHIRIS, Panayiotis; IOANNOU, Adri, Eds., Learning and collaboration technologies. Lecture Notes in Computer Science, vol 9753. Switzerland: Springer International Publishing, 2016, pp. 463-473.

CHAMBERLIN, Barbara; TRESPALACIOS, Jesús; GALLAGHER, Rachel. The learning games design model: immersion, collaboration, and outcomes-driven development.

International Journal of Game-Based Learning (IJGBL), v. 2, n. 3, p. 87-110, 2012.

CLUA, Esteban W G; BITTERNCOURT, João R. Uma nova concepção para a criação de jogos educativos. In Proceedings of the Simpósio Brasileiro de Informática na Educação, nov. 2004. 
COTE, Amanda; RAZ, Julia. In-depth interviews for games research. In LANKOSKI, Petri, BJÖRK, Staffan. Eds. Game research methods: an overview, Pittsburgh, USA: Etc Press, 2015, Cap. 7, p. 93-115.

DICKEY, Michele D. Aesthetics and design for game-based learning. New York, USA: Routledge, 2015. 160 p.

FORTES, Isabela S, et al. A cross-sectional study to assess the prevalence of DSM-5 specific learning disorders in representative school samples from the second to sixth grade in Brazil. European Child \& Adolescent Psychiatry, v. 25, p. 195-207, Apr. 2016.

FULLERTON, Tracy; SWAIN, Chris; HOFFMAN, Steven. Game design workshop: Designing, prototyping, \& playtesting games. 2.ed. USA: Elsevier, 2004. 480p.

GIL, Antonio Carlos. Como elaborar projetos de pesquisa. 4.ed. São Paulo, BR: Atlas, 2002. 175p.

GOMIDES, Mariuche R A; JÚLIO-COSTA, Anelise; ANTUNES, Andressa, M; HAASE, Vitor G. Intervenção multidisciplinar na dislexia de desenvolvimento. In FUMAGALLI, Jerusa S; NAVAS, Ana L. Dislexia do desenvolvimento e adquiridas. Eds., Brasil: Pearson. 2017, p. 344-355.

JÄRVINEN, Aki. Games without frontiers: Theories and Methods for Game Studies and Design Theories and Methods for Game Studies and Design. 2008. p.481 Ph.D. dissertation, Dept. Media Culture, University of Tampere, Tampere, FI, 2008.

KADOSH, Roi C; DOWKER, Ann; HEINE, Angela; KAUFMANN, Liane; KUCIAN, Karin. Interventions for improving numerical abilities: Present and future. Trends in neuroscience and education, v. 2, n. 2, p. 85-93, Jun. 2013.

KAUFMANN, Liane; VON ASTER, Michael. The diagnosis and management of dyscalculia. Deutsches Ärzteblatt International, v. 109, n. 45, p. 767-778, Nov. 2012.

MALONE, Thomas W. What makes things fun to learn? A study of intrinsically motivating computer games. Palo Alto, CA: Xerox,1980. 89p.

MAYER, Richard E. Computer games for learning: An evidence-based approach. London, England: MIT Press, 2014. 307p.

MILES, Matthew B; HUBERMAN, Michael A. Qualitative data analysis: An expanded sourcebook. 2.ed. London, UK: Sage, 1994, 352p.

RIEBER, Lloyd P. Seriously considering play: Designing interactive learning environments based on the blending of microworlds, simulations, and games. Educational technology research and development, v. 44, n. 2, p. 43-58, Jun. 1996.

SALEN, Katie T; ZIMMERMAN, Eric. Rules of play: Game design fundamentals. London, England: MIT Press, 2004. 688p.

SHALEV, Ruth S; GROSS-TSUR, Varda. Developmental dyscalculia. Pediatric neurology, v. 24, n. 5, p. 337-342, May. 2001.

TOBIAS, Sigmund; FLETCHER, J. D; BEDIOU, B; WIND, Alexander P; CHEN, Fei. Multimedia learning from computer games. In MAYER, Richard E. Ed. The Cambridge handbook of multimedia learning. 2.ed., New York, USA: Cambridge University Press, 2014, Cap. 31. p.762-784.

WILSON, Anna J; REVKIN, Susannah K; COHEN, David; DEHAENE, Stanislas. An open trial assessment of "The Number Race", an adaptive computer game for remediation of dyscalculia. Behavioral and brain functions, v. 2, n. 1, p. 1-16, May. 2006.

WILSON, Barbara A. Neuropsychological rehabilitation. Annual Review of Clinical Psychology, v. 4, p.141-162, Apr. 2008. 
WINN, Brian. The design, play, and experience framework. In FERDIG, Richard E. Ed., Handbook of research on effective electronic gaming in education. New York, USA: IGI global, 2008, Cap. 58, p.1010-1024.

YIN, Robert K. Estudo de caso: planejamento e métodos. 2. ed. Porto Alegre: Bookman, 2001. 205p.

\section{About the author}

\section{Matheus Cezarotto}

Postdoctoral researcher in the New Mexico State University Innovative Media Research and Extension department and its Learning Games Lab. He researches the Lab's products, working through grant development and providing instructional design expertise. His published work focuses on building a research-based understanding of instructional and information design, specifically to design meaningful educational media supporting learners' variability.

ORCID < https://orcid.org/0000-0001-6657-753X> 